\title{
Can forest associated nocturnal birds persist in oil palm agroecosystem?
}

\begin{abstract}
A high demand for palm oil has led to the continued expansion of oil palm agriculture at the expense of tropical forests and forest biotic communities in many developing countries. The response of wildlife to oil palm establishment has been shown to vary according to taxa, and many forest species may not be able to adapt to the altered landscape. Many nocturnal bird species have been recorded in oil palm agriculture. Whether such forest species can also thrive in such a landscape is not known, and their responses to habitat complexity are poorly understood. We conducted point surveys of nocturnal birds (Tytonidae, Strigiformes and Caprimulgiformes over 80 points spaced at least $800 \mathrm{~m}$ apart and revisited five times) in oil palm smallholdings at Tanjung Karang, Kuala Selangor. Environmental factors measured at each point included: average height of oil palm stands, palm density, crop richness, and distances to the nearest forest, river and road. We recorded a total of 577 individuals of seven species. Palm density and distance to river were found to positively influence nocturnal bird species richness, whereas distance to the nearest forest was found to negatively influence avian species richness. In the case of abundance, number of oil palms, crop richness, and distance to the nearest river were found to influence nocturnal bird abundance positively in the smallholdings; however, distance to the nearest forest was found to influence bird abundance negatively. These findings suggest that maintaining key vegetation structure while reducing manmade structures such as roads may benefit nocturnal bird species in the smallholdings particularly those of open and semi-open habitats. However, the number of forest-associated species remained low in the smallholdings, which may only serve as suboptimal habitat for these birds. This implies that forest-associated species may not be able to persist in such landscapes.
\end{abstract}

Keyword: Forest dependent species; Habitat heterogeneity; Nocturnal bird; Oil palm smallholding 